\title{
Social Withdrawal during Adolescence and Emerging Adulthood
}

Julie C. Bowker

SUNY University at Buffalo

Larry J. Nelson

Brigham Young University - Provo, larry_nelson@byu.edu

Andrea Markovic

SUNY University at Buffalo

Stephanie Luster

Brigham Young University - Provo

Follow this and additional works at: https://scholarsarchive.byu.edu/facpub

Part of the Other Social and Behavioral Sciences Commons

\section{Original Publication Citation}

Bowker, J. C., Nelson, L. J., ${ }^{*}$ Markovic, A. K., \& *Luster, S. S. (2014). Social withdrawal in adolescence and emerging adulthood. In R. J. Coplan \& J. C. Bowker (Eds.), A handbook of solitude: Psychological perspectives on social isolation, social withdrawal, and being alone, pp. 167-183. New York, NY: Wiley-Blackwell.

\section{BYU ScholarsArchive Citation}

Bowker, Julie C.; Nelson, Larry J.; Markovic, Andrea; and Luster, Stephanie, "Social Withdrawal during Adolescence and Emerging Adulthood" (2013). Faculty Publications. 4719.

https://scholarsarchive.byu.edu/facpub/4719

This Book Chapter is brought to you for free and open access by BYU ScholarsArchive. It has been accepted for inclusion in Faculty Publications by an authorized administrator of BYU ScholarsArchive. For more information, please contact ellen_amatangelo@byu.edu. 


\title{
Social Withdrawal during Adolescence and Emerging Adulthood
}

\author{
Julie C. Bowker, ${ }^{1}$ Larry J. Nelson, ${ }^{2}$ Andrea Markovic, ${ }^{1}$ \\ and Stephanie Luster ${ }^{2}$ \\ ${ }^{1}$ Department of Psychology, University at Buffalo, The State University of \\ New York, NY, USA \\ ${ }^{2}$ Department of Family Life, Brigham Young University, Provo, UT, USA
}

Peer relationships are of central importance for healthy psychosocial development and functioning during childhood, adolescence, and adulthood. Peers provide unique opportunities for social-cognitive growth and the development and maintenance of social skills. They also serve as important sources of emotional and social support, can foster positive feelings about the self and others, and function protectively against the effects of interpersonal stressors (Rubin, Bukowski, \& Parker, 2006). Without peer relationships, individuals might miss out on developmentally formative opportunities and experiences, such as acquiring certain socially competent skills and behaviors and forming intimate best friendships (Rubin, Coplan, \& Bowker, 2009). It is also likely that loneliness will ensue, which is a strong predictor of psychological distress, across cultures, and across the lifespan (e.g., Cacioppo, Hawkley, \& Thisted, 2010; Heinrich \& Gullone, 2006; see Asher \& Weeks, Chapter 16, this volume).

In light of this evidence, a central question addressed in this chapter is how adolescents and young adults who avoid and withdraw from peers fare in terms of their development and psychological well-being. Such individuals are often referred to as socially withdrawn (Rubin et al., 2009). Due to anxiety, fear, or preference for solitary activities (Coplan \& Armer, 2007), socially withdrawn individuals avoid social situations involving unfamiliar and familiar peers and, as a result, spend more time alone than their more sociable counterparts. Although they might encounter rejecting and hostile peers, it is important to emphasize that socially withdrawn individuals spend considerable time in solitude because they choose to be alone. 
In the past 30 years, social withdrawal during childhood has been identified as one of the strongest risk factors for psychopathology (Rubin et al., 2009). However, considerably less is known about the effects of withdrawing from peers during adolescence and emerging adulthood (Bowker, Rubin, \& Coplan, 2012). This research gap that is surprising given that the importance of involvement in close and intimate peer relationships for psychological well-being increases throughout adolescence and into emerging adulthood (Rubin, Bukowski, et al., 2006), but so too does the need for and value placed on solitude and alone time (Larson, 1990). The study of social withdrawal beyond the childhood years is an emerging area of research, and this chapter represents the first review of this literature focused specifically on adolescents and emerging adults.

Throughout this chapter, we attempt to synthesize the research on social withdrawal with developmental theory and research to form a comprehensive view of social withdrawal during the adolescent and emerging adulthood developmental periods. We contend that social withdrawal continues to be a risk factor for maladjustment beyond the childhood years but that future research should more carefully consider the developmental characteristics of adolescence and emerging adulthood when selecting adjustment outcomes and interpreting results. We also hope that there will be an increased number of studies considering different motivations for withdrawal and associated outcomes in the next several years. A review of the extant literature and a more detailed discussion of future research directions are included in subsequent text, but we first review some of the defining characteristics of the adolescent and emerging adulthood developmental periods.

\section{Developmental Periods of Adolescence and Emerging Adulthood}

\section{Adolescence}

The adolescent developmental period refers to the ages of 10-22 years. Adolescence is often described as a period of developmental change and transition connecting the childhood and adulthood/emerging adulthood developmental periods (Collins \& Steinberg, 2006). Developmental psychologists distinguish between three subperiods of adolescence, early adolescence (10-14 years), middle adolescence (14-18 years), and late adolescence (18-22 years), although in recent years, the late adolescent developmental period has been studied as part of emerging adulthood (Arnett, 2004).

There are no overarching theories of adolescent development. Instead, theories such as social learning theory (Bandura \& Walters, 1963), interpersonal theories (Sullivan, 1953), and social-cognitive theories (e.g., Piaget, 1932) are used to explain different types of functioning during adolescence, as well as different 
types of developmental changes. Among the most commonly studied changes by psychologists are those related to biological maturation (e.g., pubertal developmental changes including changes in weight and height and the development of sexual characteristics), cognition (e.g., the development of abilities to think abstractly and about hypothetical problems, cognitive changes that lead to introspection and rumination), and social relationships (e.g., increased time spent with nonfamilial individuals, the development of other-sex peer relationships, increased importance of getting along with and having successful peer relationships; Collins \& Steinberg, 2006). Of course, each type of change does not occur independently, but rather is influenced by and influences other types of changes. For instance, pubertal development often leads to emerging social and romantic interests in other-sex peers; involvement with other-sex peers can lead to increases in self-consciousness, particularly about physical appearance and puberty-related changes (Ricciardelli \& McCabe, 2001; Lieberman, Gauvin, Bukowski, \& White, 2001).

The changes in social relationships that occur during adolescence are particularly important when considering the consequences of avoiding such relationships. For example, as adolescents first begin to spend more time with their peers than their families (Rubin, Bukowski, et al., 2006), their peer experiences become more strongly influential on their psychological well-being. These findings have led to suggestions that socially withdrawn adolescents may continue to experience psychological difficulties well after the childhood years and that some of their psychological difficulties may actually get worse (Rubin et al., 2009). However, another developmental change is the increased value placed on privacy and alone time during adolescence (Larson, 1990). Several studies on this topic demonstrate that solitude becomes more beneficial to psychological health and well-being throughout the adolescent period (Larson, 1990, 1997). This raises the alternative hypothesis, namely, that some of socially withdrawn adolescents' difficulties may actually diminish with age. The studies by Larson and colleagues, however, indicate that solitude may be best for psychological adjustment during adolescence when adolescents engage in moderate amounts (30\% of waking time). For instance, in one study, adolescents who engaged in moderate amounts of solitude reported more positive adjustment relative to adolescents who never engaged in solitude and those who engaged in solitude often (Larson \& Csikszentmihalyi, 1978). Thus, although some solitude may be helpful, large amounts (i.e., as typically experienced by socially withdrawn individuals) may continue to have deleterious effects.

\section{Emerging adulthood}

There is admittedly a great deal of individual variation in the paths that young people take as they leave adolescence and enter and then develop throughout the third decade of life. Culture, socioeconomic status, and individual characteristics shape the variety of responsibilities, expectations, and opportunities that impact individuals during this period of time. Given this variance, there is also not one 
theory that fully captures all developmental pathways out of adolescence and through the third decade of life. However, emerging adulthood theory (Arnett, 2000) is useful in capturing some of the unique aspects of this time period that will lay the foundation for understanding the potential developmental impact of social withdrawal during this period of development.

Arnett (2004) has characterized emerging adulthood (18-27 years) as including five important features. First, it is an age of feeling in-between as most emerging adults do not see themselves as either an adolescent or an adult. Second, emerging adulthood is an age of possibilities as most young people are extremely optimistic and have high hopes for the future. Third, this period of development is an age of instability because it tends to be marked by instability in work, relationships, education, and residential status. Next, emerging adulthood is characterized as an age of identity explorations because many emerging adults are free to explore identities in the areas of education, work, love, and worldviews. Finally, emerging adulthood is a self-focused age of life. This is not meant to suggest that emerging adults are necessarily self-centered but are rather free from social obligations and other responsibilities that allow for a productive focus on the self.

Again, despite the cultural, socioeconomic, and other influences that might limit the extent to which young people experience these various features, these factors reflect some of the aspects of the time period for many that might be impacted by social withdrawal. Furthermore, regardless of this variation, the time period following adolescence is when most young people start the process of becoming self-reliant, autonomous individuals capable of independent decision making and actions. For some, this transition into autonomous roles might occur immediately after adolescence (or in adolescence), whereas for others it might be delayed well into the late 20 s or early 30 s. Regardless, it is during the period after adolescence that individuals often find themselves in new social settings (e.g., college classrooms, workplace, military) and facing new developmental challenges (e.g., independent decision making, identity development, cohabitation/committed relationships) for which social withdrawal might have significant implications.

\section{Correlates and Consequences of Social Withdrawal in Adolescence and Emerging Adulthood}

\section{Social withdrawal and adolescence}

The majority of the research on the correlates and consequences of avoiding and withdrawing from peers has focused on young children and elementary schoolaged children (Bowker, Rubin, et al., 2012; Rubin et al., 2009). However, the limited research on adolescent social withdrawal has indicated that social withdrawal is a relatively stable construct across childhood and into adolescence (e.g., Oh et al., 2008). That is, children who avoid their peers during childhood tend to continue to 
do so after they transition into adolescence. And despite the aforementioned increased importance of privacy and alone time during adolescence (e.g., Larson, 1990), withdrawn adolescents appear to experience difficulties with their peers that are similar to the difficulties that they encounter when they are younger, including peer victimization and peer exclusion (Rubin, Wojslawowicz, RoseKrasnor, Booth-LaForce, \& Burgess, 2006; Oh et al., 2008). However, several studies have failed to find significant linkages between social withdrawal and peer rejection, as found in studies of children (e.g., Bowker \& Raja, 2011). Peer rejection reflects active dislike of peers, whereas peer exclusion and peer victimization involve behaviors that exclude (e.g., not allowing an adolescent to join into a group activity) and abuse peers (e.g., repeated name-calling, physical victimization). Therefore, it is possible that adolescents begin to respect socially withdrawn adolescents' decisions to avoid their peers, perhaps because of the changes in their own needs for privacy. But adolescents might still not wish to be in their company, likely because their shy and timid behaviors contrast sharply with adolescent social norms and expectations for social interaction and relationship involvement. Adolescents may also continue to victimize withdrawn adolescents because they continue to be viewed as weak and easy targets that are unlikely to retaliate or fight back (Rubin, Wojslawowicz, et al., 2006).

Given the importance of interacting with and getting along with peers for positive psychological adjustment during adolescence, it should not be too surprising that growing evidence indicates that socially withdrawn adolescents fare worse psychologically than their nonsocially withdrawn counterparts. Psychological maladaptation outcomes that are concurrently associated with adolescent social withdrawal include loneliness, anxiety, and depressive symptoms (e.g., Mounts, Valentiner, Anderson, \& Boswell, 2006; Muris, Merckelbach, Schmidt, Gadet, \& Bogie, 2001; Woodhouse, Dykas, \& Cassidy, 2012). There is also evidence that the presence and persistence of withdrawal during middle to late childhood in particular place youth at increased risk for the development of psychological difficulties during adolescence including low self-esteem, as well as a wide array of clinically significant anxiety problems (e.g., social phobia, panic/agoraphobia, specific phobia) and depression (e.g., Fordham \& Stevenson-Hinde, 1999; Goodwin, Fergusson, \& Horwood, 2004; Karevold, Ystrom, Coplan, Sanson, \& Mathiesen, 2012; Prior, Smart, Sanson, \& Oberklaid, 2000). These latter findings suggest that social withdrawal may actually become a stronger risk factor for clinically significant adjustment outcomes during the adolescent developmental period.

Tests of mediation have shown that peer difficulties, such as peer exclusion, explain, in part, some of the psychological difficulties associated with both child and adolescent social withdrawal (e.g., Bowker \& Raja, 2011; Gazelle \& Rudolph, 2004). It has also been found that withdrawn adolescents who experience high levels of peer adversity display higher levels of social avoidance (e.g., make fewer social initiatives, are easily discouraged by social setbacks; Gazelle \& Rudolph, 2004) and become more withdrawn over time relative to withdrawn youth who 
experience low levels of peer adversity (Booth-LaForce \& Oxford, 2008; BoothLaForce et al., 2012; Oh et al., 2008). Oh et al. also found that certain same-sex friendship factors (e.g., friendlessness, friendship instability, having a withdrawn friend) predict increased social withdrawal over time, highlighting the importance of socially withdrawn adolescents' group and dyadic peer relations for their psychological well-being. Finally, there is evidence that many withdrawn adolescents have negatively biased information processing tendencies (e.g., self-blame tendencies; Burgess, Wojslawowicz, Rubin, Rose-Krasnor, \& Booth-LaForce, 2006; Findlay, Coplan, \& Bowker, 2009), which have also been to shown to explain why socially withdrawn adolescents commonly experience feelings of loneliness, negative affect, and social anxiety.

The extant literature has led Rubin and colleagues (e.g., Rubin et al., 2009) to posit that a negative feedback loop exists for socially withdrawn children and adolescents. Anxiety, fears, and self-doubt lead to shy and timid behaviors that invite negative peer treatment, which, in turn, reinforces their fears, anxieties, negative cognitions, and socially withdrawn behaviors. And yet, not all socially withdrawn adolescents have social-cognitive biases and experience psychosocial maladjustment. For example, recent work by Markovic, Rose-Krasnor, and Coplan (2013) has shown that shy young adolescents who perceive their personality to be malleable are less likely to display negative self-attributions and select avoidant strategies to cope with peer conflict relative to their shy counterparts who consider their personality to be fixed.

Other research (e.g., Bowker, Markovic, Cogswell, \& Raja, 2012) demonstrates that withdrawn adolescents who display additional atypical and socially inappropriate behaviors (e.g., overtly aggressive behavior) are at greatest risk for peer adversity, but less is known about peer-valued characteristics that may help buffer withdrawn adolescents against peer difficulties. Withdrawn adolescents who experience low levels of group-level peer adversity have been shown to display fewer depressive symptoms and higher levels of prosocial behavior toward their peers (Gazelle $\&$ Rudolph, 2004) and become less withdrawn over time (BoothLaForce \& Oxford, 2008; Oh et al., 2008). Research has also shown that withdrawn adolescents with friends are viewed as more sociable by their peers relative to their withdrawn counterparts without friends (Rubin, Wojslawowicz, et al. 2006) and are less likely to self-blame for problems involving their mutual best friends (Burgess et al., 2006). In addition, Booth-LaForce et al. (2012) found that those withdrawn-excluded adolescents who spent more free time with their mothers displayed decreases in their withdrawal over time. These latter findings suggest that involvement in close dyadic relationships (e.g., friends, parents) may provide withdrawn adolescents with just enough positive social interaction to help ameliorate some of their social fears and improve their confidence in social situations. In turn, these withdrawn adolescents may become more positively received by their peers because their social behavior comes to more closely approximate the norms of sociability prevalent during the adolescent developmental 
period. However, relative to the research on social withdrawal and group-level peer experiences, only a limited literature has examined the importance of dyadic relationships in the lives of young adolescents who are socially withdrawn.

Taken together, it appears that social withdrawal continues to be a strong risk factor for social, emotional, and psychological difficulties during adolescence. There is also growing evidence of significant heterogeneity in the outcomes associated with adolescent social withdrawal, which may be explained, in part, by variability in close relationships and social-cognitive tendencies. So far, much of the research has focused on social withdrawal during adolescence that is motivated by anxiety or fear, which has been referred to as shyness, anxious-withdrawal, and shyness-sensitivity (also anxious-solitude; e.g., Gazelle \& Rudolph, 2004; Oh et al., 2008). However, some adolescents' social withdrawal may be due to social disinterest (unsociability) or strong preferences to avoid others (avoidance; Coplan \& Armer, 2007). And Asendorpf, Coplan, and others have proposed that the outcomes associated with social withdrawal may depend on the reasons for or motivation underlying the withdrawal (e.g., Asendorpf, 1990; Coplan, Prakash, O’Neil, \& Armer, 2004). Studies of different types of social withdrawal during childhood indicate that shyness/anxious-withdrawal is more strongly associated with problematic adjustment indices relative to social disinterest/ unsociability, but we know very little about the correlates and consequences of avoidance in childhood and adolescence, as well as the risk associated with unsociability relative to shyness during adolescence (see Bowker \& Raja, 2011; Bowker et al., 2012, Coplan et al., 2013, for recent exceptions).

The relative neglect of social withdrawal subtypes in this area of research has limited our understanding about which socially withdrawn adolescents may be most at risk for difficulties and how to best target interventions. Likewise, the emphasis on social withdrawal in relation to school-based peer relationships has resulted in little knowledge about social withdrawal in relation to other significant adolescent developmental changes, such as those related to puberty and cognition, and the impact of social withdrawal in contexts outside of the school that first become relevant to functioning during adolescence, such as places of employment. Do the cognitive changes that occur in adolescence contribute to the enhanced psychological risk associated with adolescent social withdrawal? Might early versus late pubertal development exacerbate socially withdrawn adolescents' fragile selfconcepts and contribute to their social wariness? Perhaps socially withdrawn adolescents' behavior is judged less harshly outside of the school context. These questions should be the topic of future investigations. There is also a need for research on how socially withdrawn adolescents fare with other-sex peers. Most of the research on the peer experiences of socially withdrawn adolescents has focused exclusively on group-level peer difficulties in general (e.g., the extent to which an adolescent is excluded by both same-sex and other-sex peers) or same-sex friendships (e.g., Rubin, Wojslawowicz, et al., 2006). Thus, it is not known whether socially withdrawn adolescents struggle more with same- or other-sex peers or whether 
they are able to form other-sex friendships and romantic relationships, which become increasingly common during early and middle adolescence (Rubin, Bukowski, et al., 2006). Another question that merits examination is whether the correlates and consequences of adolescent social withdrawal differ in Western and non-Western societies, which may have different norms and expectations for social behaviors and relationships. Bowker and Raja (2011) found that self-reported shyness, unsociability, and avoidance during early adolescence in India were not related significantly to peer rejection and that the associations between the subtypes of withdrawal and peer exclusion and loneliness were smaller in magnitude than typically found in studies of socially withdrawn children in Western societies. Does any type of socially withdrawn behavior during adolescence carry less risk in non-Western societies because the behavior contrasts less sharply with cultural norms and expectations? Clearly, there is still much to discover about for whom, when, and where withdrawing from peers during adolescence poses the greatest social and psychological risk.

\section{Social withdrawal and emerging adulthood}

The heading for this section of the chapter is "social withdrawal and emerging adulthood" rather than "social withdrawal during emerging adulthood" for a specific reason. There are two different but equally important lines of research that describe the impact of withdrawal on development in emerging adulthood. The first line of work has attempted to understand how withdrawal early in life (i.e., childhood, adolescence) predicts outcomes in emerging adulthood, and the second line of research examines the correlates and consequences of withdrawal during emerging adulthood.

First, there is an existing body of longitudinal work showing that shyness early in life predicts negative outcomes in emerging and young adulthood. For example, Caspi and Silva (1995) found that children rated high on shyness at age 3 scored low on measures of impulsivity, danger seeking, aggression, and social potency (i.e., forceful, decisive, fond of influencing others, and leadership roles; Caspi $\&$ Silva) at age 18. Other similar studies have found early shyness to be linked to later introversion and cautiousness (Kagan $\&$ Moss, 1962), unassertiveness, depression, and fewer sources of social support (Caspi, 2000) and delayed entry into adult roles (e.g., marriage, parenthood, and stable careers; Asendorpf, Denissen, \& van Aken, 2008; Caspi, Elder, \& Bem, 1988; Kerr, Lambert, \& Bem, 1996). Using a different methodological approach to understand how withdrawal at young ages is linked to development in emerging adulthood, a recent study linked retrospective assessments of Australian and Korean emerging adults' shyness and unsociability in adolescence (Kim, Rapee, Oh, \& Moon, 2008) to functioning in emerging adulthood. Taken together, this line of research suggests that individuals who are socially withdrawn, especially shy, as children and adolescents may enter the third decade of life already at risk for negative outcomes. 
Although interesting and informative, retrospective and longitudinal studies do not provide insight into how social withdrawal during emerging adulthood may impact the development of individuals currently in emerging adulthood. Specifically, it is important to examine the implications of various forms of withdrawal on individuals' attitudes, beliefs, and behaviors in the context of the unique features of a time period. Therefore, the remainder of this chapter will focus specifically on the correlates and consequences of social withdrawal in emerging adulthood.

There is evidence that social withdrawal in all of its various forms (a topic we will address later) is problematic to important aspects of emerging adulthood. For example, identity development has been identified as an important feature of emerging adulthood (e.g., Arnett, 2000; Erikson, 1968), and studies have found that compared to their non-shy peers, shy emerging adults tend to struggle with both exploration and achievement. Shy individuals have been found to report less identity commitment than their peers (Barry, Nelson, \& Christofferson, 2013). In the area of career exploration and commitment, shy individuals report lower career identity levels and, in general, less mature attitudes toward career planning and exploration (Hamer \& Bruch, 1997). Furthermore, Phillips and Bruch (1988) found that shy undergraduates engaged in less career information-seeking, were more undecided about a potential career, and expressed less interest in interpersonally oriented career fields.

Another important aspect of emerging adulthood is centered around social interactions with peers (e.g., roommates, classmates, workmates) and relationships (e.g., romantic partners, friends, parents). Studies have found that compared to the non-withdrawn peers, shy and withdrawn emerging adults engage in less dating (Leck, 2006), feel less competent in romantic relationships and less socially accepted by peers (Nelson et al., 2008), and report lower-quality relationships with friends, romantic partners, and parents (Barry et al., 2013; Nelson et al., 2008; Rowsell \& Coplan, 2012).

In laboratory-based work, studies have shown that in conversations with a stranger, shy individuals report greater frequency of negative and anxious thoughts (especially for men), fewer positive thoughts regarding the interaction, more overt behavioral signs of anxiety, an increase in somatic arousal, more time self-focusing, and, in general, fewer vocal exchanges (Bruch, Gorsky, Collins, \& Berger, 1989; Melchior \& Cheek, 1990). In sum, social interactions and relationships seem to be an area for which social withdrawal in emerging adulthood appears to be a significant risk factor.

Furthermore, emerging adulthood is a period of exploration for young people including in areas related to sexuality. Emerging evidence suggests that shyness influences sexual attitudes and behaviors among both young men and women. For men, shyness has been associated with more permissive sexual attitudes (e.g., the acceptability of premarital sex, noncommittal sex, and pornography) as well as increased levels of masturbation and pornography use for males (Luster, Nelson, Poulsen, \& Willoughby, in press). Though these behaviors may be normative in 
emerging adulthood, elevated levels of solitary sexual behavior may exacerbate existing social tendencies and/or relational deficiencies. In contrast, for women, shyness has been associated with more conservative sexual attitudes and fewer sexual partners (Luster et al., in press). Thus, this emerging line of work suggests that withdrawal might influence young people's beliefs and behaviors in areas of exploration common in emerging adulthood.

Finally, with emerging adulthood being a time marked by instability in work, relationships, education, and residential status (Arnett, 2004), some young people struggle in a number of areas, and this appears to be the case for socially withdrawn emerging adults. Again, compared to their non-shy peers, shy emerging adults have more academic struggles (Hojat, Vogel, Zeleznik, \& Bornstein, 1988), experience greater loneliness in the transition to college (Mounts et al., 2006), and, in general, report lower levels of happiness (Neto, 2001), well-being (Hotard, McFatter, McWhirter, \& Stegall, 1989), religious strength (Barry et al., 2013), and self-esteem and self-perceptions (Nelson et al., 2008), as well as higher levels of anxiety and depression (Nelson et al., 2008).

Taken together, these findings lend support to the notion that social withdrawal, especially shyness, may have the potential to be problematic in emerging adulthood (with some possible protective features) because of the instability, expectations for greater self-reliance, focus on exploration of beliefs and behaviors, and increased demand on individuals to engage in social interactions and relationships. However, the emerging picture is cloudy at best because nearly all of the work conducted with samples of emerging adults has used global and differing definitions of shyness. For example, some researchers have focused on the emotional component of shyness (e.g., fear; "I feel tense when I am with people I don't know well”; Mounts et al., 2006). Others have attempted to incorporate both the emotions (i.e., fear, anxiety) and cognitions associated with shyness (e.g., "I feel painfully self-conscious when I'm around strangers"; Melchior $\&$ Cheek, 1990). Still others have focused on the more behavioral components of shyness with items such as talkative (reverse coded), quiet, outgoing (reverse coded), and shy (e.g., Nelson et al., 2008).

These examples point to multiple ways in which the term shyness has been operationalized. However, that is just one of the murky features of studying social withdrawal in emerging adulthood. There is also a range of behaviors studied in emerging adulthood that reflect different forms of social withdrawal, or in other words, different reasons for withdrawing. For example, there is evidence that whereas some individuals may remove themselves from social settings due to fear and wariness, others do so out of social disinterest or unsociability (Nelson, 2013). Often, operational definitions do not tap these potential differences in the reasons for withdrawing from social settings. For example, studies that take a more global approach to the study of withdrawal (i.e., operationalizing shyness as talkative (reverse coded), quiet, outgoing (reverse coded), and shy; e.g., Nelson et al., 2008) fail to capture the potential differences in the motivations for withdrawing. 
Also, different perspectives and terms are often employed for overlapping constructs when assessing different types of withdrawal. For example, Barry et al. (2013) employed the term asocial to capture any withdrawn behaviors not driven by fear or anxiety. Often those who are shy or engage in social withdrawal are labeled as introverts or low sociable in the personality literature (Briggs, 1988; Cheek \& Buss, 1981; Eisenberg, Fabes, \& Murphy, 1995; Jones \& Briggs, 1984). It is important to note that though shyness may incorporate similar behavioral characteristics to those who are introverted or low sociable, they are unique constructs because they differ in motivations. Introverts and those who are low sociable are characterized by a preference for solitary activity, but these individuals likely experience minimal difficulty interacting with others when required (Buss \& Plomin, 1984; Eysenck, 1956). On the other hand, shy individuals may have a strong preference for social activity but are restrained by their experiences of fear and anxiety (Henderson \& Zimbardo, 2001). Those who are introverted may specifically desire social environments that are low in stimulation, whereas individuals who are shy may be desirous of stimulation equal to that of extroverts (Henderson, Zimbardo, \& Carducci, 2010). Taken together, though various perspectives, including the personality literature, have often used the terms asocial, introvert, low sociable, and shy as interchangeable and they may have some overlap, these terms are not synonymous (Briggs, 1988).

In sum, the study of social withdrawal in emerging adulthood suggests that social withdrawal may be of developmental concern, but there are numerous conceptual issues that require further clarification in order to better understand the implications of past work and to guide future work. Specifically, the extant work has often (i) taken global approaches to the study of withdrawal, (ii) assessed different aspects (i.e., emotional, behavioral, or cognitive) of specific constructs (e.g., shyness), (iii) used a variety of terms for similar constructs (e.g., asocial, introverted), and/ or (iv) failed to account for the motivations behind the behaviors.

In order to bring greater clarity and organization to the study of social withdrawal in emerging adulthood (and also adolescence), it might be useful to employ the approach-avoidance models of social withdrawal (Asendorpf, 1990, 1993; Gray, 1972) described previously (i.e., shy, unsociable, avoidant) as they are useful in understanding why individuals (i.e., motivations) may withdraw from social settings. Indeed, recent work in emerging adulthood suggests that this is a useful and informative framework for better understanding how various forms of social withdrawal might be linked to various correlates and outcomes in emerging adulthood.

Specifically, Nelson (2013) found that shyness, avoidance, and unsociable behaviors were identifiable as three distinct forms of social withdrawal in emerging adulthood and found that each one was uniquely related to indices of maladjustment. Shy individuals (high approach and high avoidance motivations) struggled with self-worth, fear of negative evaluations from others, depression, social comparisons, suicidal ideations, and emotional dysregulation. Avoidant (low approach and 
high avoidance motivations) individuals also reported problems in regard to self-worth, depression, self-harm, suicidal ideations, and emotional dysregulation. Also, both shy and avoidant individuals reported lower-quality relationships with best friends, romantic partners, mothers, and fathers compared to the individuals in the study's comparison group. Interestingly, there were very few differences between the unsociable and comparison groups. The unsociable (low approach and low avoidance motivations) individuals reported higher levels of depression than the comparison group but otherwise did not differ from the control group on any other indicator of internalizing or relationship problems.

These distinctions underscore the conceptual and empirical differences between the groups and, therefore, underscore the need to understand and study differences between forms of social withdrawal in emerging adulthood based on approachavoidance motivations. Indeed, continued use of global measures of withdrawal will mask what appear to be important differences in the development of individuals who withdraw from social settings but who do so for very different reasons. Given the unique features of emerging adulthood, it is critically important that future work examine the correlates and outcomes of each form of social withdrawal in the third decade of life.

For example, in striving to become more autonomous and self-reliant, emerging adults are required to take on greater responsibility in acting for themselves with many important tasks and contexts requiring social interactions (e.g., dating, hanging out in groups, work environments, apartments/dorms, classrooms, and possible religious or volunteer organizations). Therefore, there may be serious ramifications for individuals who choose not to or are unable to successfully interact with others during emerging adulthood. For instance, social withdrawal in all of its forms might have ramifications in individuals' pursuit of an education. It is possible that some shy and avoidant individuals do not enroll in college because their avoidance motivations prevent them from doing so. For those who do enroll, fear or avoidance tendencies might keep them from raising questions or otherwise participating in class, seeking help from professors, or participating in resumebuilding activities (i.e., clubs, internships, mentored activities) that would enhance their college experience.

Another important aspect of emerging adulthood is the changing nature of relationships with peers, romantic partners, and parents. There is evidence that social withdrawal is linked to lower relationship quality in all of these areas (i.e., friends, romantic partners, and parents; Barry et al., 2013; Nelson et al., 2008), but, again, most of this work employs global ratings of shyness rather than subtypes of withdrawal. Work is needed to examine various aspects of relationships (quality, satisfaction, communication, sexuality, empathy, etc.) for each form of social withdrawal. Indeed, the trajectories of relationship development and maintenance might vary depending on the motivations for withdrawing. For example, for shy individuals, researchers might investigate whether or not their approach motivation leads them to seek out and enter romantic relationships, but then their avoidance 
motivations contribute (i.e., less empathy, communication, self-disclosure; Luster, Nelson, \& Busby, in press) to their experiencing more low-quality relationships than their more sociable peers. Furthermore, it will be important to learn how unsociable individuals form and maintain romantic relationships when they do not have a strong motivation to be with other people. In general, various motivations for withdrawal might impact, among other issues related to romantic relationships, whether or how often one dates and cohabits and beliefs about and timing of marriage.

Subtypes of withdrawal might also influence parent-child relationships. Emerging adults often report a desire to see their relationships with their parents mature into one of equals (e.g., Nelson et al., 2007). Hence, there is little if any evidence that the parent-child relationship diminishes during emerging adulthood; instead, it changes and matures. However, there is little if any work examining the association between subtypes of withdrawal and various aspects of the parent-child relationship including relationship quality, parental knowledge, or parenting styles. It would also be important to understand whether various motivations for withdrawing from social settings might lead some individuals to remain at home with their parents for longer. Although media depictions of those who live at home with their parents often portray these individuals as being more socially inhibited, there are no studies that have examined how different forms of withdrawal might be related to various living arrangements including remaining at home with parents. In sum, emerging evidence seems to suggest that there is reason to be concerned about the risk factors that exist in emerging adulthood for those who withdraw from social interaction, especially avoidant and shy individuals, but points to the possibility that there might be a number of adaptive features as well especially for unsociable emerging adults. This underscores the need for future work to explore for both adaptive and maladaptive correlates and outcomes related to shy, avoidant, and unsocial withdrawal in emerging adulthood.

\section{Conclusion}

Taken together, there is much work to be done to better understand the developmental trajectory of individuals who engage in various forms of social withdrawal. Adolescence is a unique period characterized by biological, cognitive, and social changes, and emerging adulthood is unique as young people strive to become selfreliant, autonomous individuals. The nature of relationships, exploration, identity development, instability, and other features of both developmental periods raise concern about the developmental trajectories for those who may choose to withdraw from or, due to fear, struggle with peer relationships and social interactions. Therefore, the study of social withdrawal in adolescence and emerging adulthood deserves much more developmentally informed theoretical and empirical attention. 


\section{References}

Arnett, J. J. (2000). Emerging adulthood: A theory of development from the late teens through the twenties. American Psychologist, 5, 468-480.

Arnett, J. J. (2004). Emerging adulthood: The winding road from the late teens through the twenties. New York: Oxford University Press.

Asendorpf, J. B. (1990). Beyond social withdrawal: Shyness, unsociability, and peer avoidance. Human Development, 33, 250-259.

Asendorpf, J. B. (1993). Beyond temperament: A two-factor coping model of the development of inhibition during childhood. In K. H. Rubin \& J. Asendorpf (Eds.), Social withdrawal, inhibition, and shyness in childhood (pp. 265-290). Hillsdale, NJ: Erlbaum.

Asendorpf, J. B., Denissen, J. J. A., \& van Aken, M. A. G. (2008). Inhibited and aggressive preschool children at 23 years of age: Personality and social transitions into adulthood. Developmental Psychology, 44, 997-1011.

Bandura, A., \& Walters, R. H. (1963). Social learning theory and personality development. New York: Holts, Rinehart and Winston.

Barry, C. M., Nelson, L. J., \& Christofferson, J. (2013). Asocial and afraid: An examination of shyness and anxiety in emerging adulthood. Journal of Family Studies, 19, 2-18.

Booth-LaForce, C., Oh, W., Kennedy, A. E., Rubin, K. H., Rose-Krasnor, L., \& Laursen, B. (2012). Parent and peer links to trajectories of anxious withdrawal from grades 5 to 8 . Journal of Clinical Child and Adolescent Psychology, 41(2), 138-149.

Booth-LaForce, C., \& Oxford, M. L. (2008). Trajectories of social withdrawal from grades 1 to 6: Prediction from early parenting, attachment, and temperament. Developmental Psychology, 44(5), 1298-1313.

Bowker, J. C., Markovic, A., Cogswell, A., \& Raja, R. (2012). Moderating effects of aggression on the associations between social withdrawal subtypes and peer difficulties during early adolescence. Journal of Youth and Adolescence, 14, 995-1007.

Bowker, J. C., \& Raja, R. (2011). Social withdrawal subtypes during early adolescence in India. Journal of Abnormal Child Psychology, 39, 201-212.

Bowker, J. C., Rubin, K., \& Coplan, R. (2012). Social withdrawal during adolescence. In R. Levesque (Ed.), Encyclopedia of adolescence. New York: Springer.

Briggs, S. R. (1988). Shyness: Introversion or neuroticism? Journal of Research in Personality, 22, 290-307.

Bruch, M. A., Gorsky, J. M., Collins, T. M., \& Berger, P. A. (1989). Shyness and sociability reexamined: A multicomponent analysis. Journal of Personality and Social Psychology, 57, 904-915.

Burgess, K., Wojslawowicz, J., Rubin, K., Rose-Krasnor, L., \& Booth-LaForce, C. (2006). Social information processing and coping styles of shy/withdrawn and aggressive children: Does friendship matter? Child Development, 77, 371-383.

Buss, A. H., \& Plomin, R. (1984). Temperament: Early developing personality traits. Hillsdale, NJ: Erlbaum.

Cacioppo, J. T., Hawkley, L. C., \& Thisted, R. A. (2010). Perceived social isolation makes me sad: 5-Year cross-lagged analyses of loneliness and depressive symptomatology in the Chicago Health, Aging, and Social Relations Study. Psychology and Aging, $25,453-463$. 
Caspi, A. (2000). The child is father of the man: Personality continuities from childhood to adulthood. Journal of Personality and Social Psychology, 78, 158-172.

Caspi, A., Elder, G. H., \& Bem, D. J. (1988). Moving away from the world: Life-course patterns of shy children. Developmental Psychology, 24, 824-831.

Caspi, A., \& Silva, P. A. (1995). Temperamental qualities at age three predict personality traits in young adulthood: Longitudinal evidence from a birth cohort. Child Development, 66, 486-498.

Cheek, J. M., \& Buss, A. H. (1981). Shyness and sociability. Journal of Personality and Social Psychology, 41, 330-339.

Collins, W. A., \& Steinberg, L. (2006). Adolescent development in interpersonal context. In W. Damon \& R. M. Lerner (Series Eds.) \& N. Eisenberg (Vol. Ed.), Handbook of child psychology: Vol. 3. Social, emotional, and personality development (6th ed., pp. 1003-1067). Hoboken, NJ: Wiley.

Coplan, R. J., \& Armer, M. (2007). A “multitude” of solitude: A closer look social withdrawal and nonsocial play in early childhood. Child Development Perspectives, 1, 26-32.

Coplan, R. J., Prakash, K., O’Neil, K., \& Armer, M. (2004). Do you “want” to play? Distinguishing between conflicted shyness and social disinterest in early childhood. Developmental Psychology, 40, 244-258.

Coplan, R. J., Rose-Krasnor, L., Weeks, M., Kingsbury, A., Kingsbury, M., \& Bullock, A. (2013). Alone is a crowd: Social motivations, social withdrawal, and socio-emotional functioning in later childhood. Developmental Psychology, 49, 861-875.

Eisenberg, N., Fabes, R. A., \& Murphy, B. C. (1995). Relations of shyness and low sociability to regulation and emotionality. Journal of Personality and Social Psychology, 68, 505-517.

Erikson, E. H. (1968). Identity: Youth and crisis. New York: W. W. Norton.

Eysenck, H. J. (1956). The questionnaire measurement of neuroticism and extraversion. Rivista de Psicologia, 50, 113-140.

Findlay, L. C., Coplan, R. J., \& Bowker, A. (2009). Keeping it all inside: Shyness, internalizing coping strategies and socio-emotional adjustment in middle childhood. International Journal of Behavioural Development, 33(1), 47-54.

Fordham, K., \& Stevenson-Hinde, J. (1999). Shyness, friendship quality, and adjustment during middle childhood. Journal of Child Psychology and Psychiatry, 40(5), 757-768.

Gazelle, H., \& Rudolph, K. D. (2004). Moving toward and away from the world: Social approach and avoidance trajectories of anxious solitary youth. Child Development, 75(3), 829-849.

Goodwin, R. D., Fergusson, D. M., \& Horwood, L. J. (2004). Early anxious/withdrawn behaviours predict later internalising disorders. Journal of Child Psychology and Psychiatry, 45(4), 874-883.

Gray, J. A. (1972). The psychophysiological nature of introversion-extraversion: A modification of Eysenck's theory. In V. D. Nebylitsyn \& J. A. Gray (Eds.), Biological bases of individual behaviour. New York/London: Academic Press.

Hamer, R. J., \& Bruch, M. A. (1997). Personality factors and inhibited career development: Testing the unique contribution of shyness. Journal of Vocational Behavior, 50(3), 382-400.

Heinrich, L. M., \& Gullone, E. (2006). The clinical significance of loneliness: A literature review. Clinical Psychology Review, 26, 695-718.

Henderson, L., \& Zimbardo, P. (2001). Shyness, relationship to social anxiety and social phobia. In S. Hofman \& P. diBartolo (Eds.), Social phobia (pp. 46-65). New York: Allyn \& Bacon. 
Henderson, L., Zimbardo, P., \& Carducci, B. (2010). Shyness. Corsini Encyclopedia of Psychology. doi: 10.1002/9780470479216.corpsy0870

Hojat, M., Vogel, W. H., Zeleznik, C., \& Bornstein, B. D. (1988). Effects of academic and psychosocial predictors of performance in medical school on coefficients of determination. Psychological Reports, 63(2), 383-394.

Hotard, S. R., McFatter, R. M., McWhirter, R. M., \& Stegall, M. E. (1989). Interactive effects of extraversion, neuroticism, \& social relationships on subjective well-being. Journal of Personality and Social Psychology, 57, 321-331.

Jones, W. H., \& Briggs, S. R. (1984). The self-other discrepancy in social shyness. In R. Schwarzer (Ed.), The self in anxiety, stress and depression (pp. 93-107). Amsterdam: North Holland.

Kagan, J., \& Moss, B. A. (1962). Birth to maturity. New York: Wiley.

Karevold, E., Ystrom, E., Coplan, R. J., Sanson, A. V., \& Mathiesen, K. S. (2012). A prospective longitudinal study of shyness from infancy to adolescence: Stability, agerelated changes, and prediction of socio-emotional functioning. Journal of Abnormal Child Psychology, 40(7), 1167-1177.

Kerr, M., Lambert, W. W., \& Bem, D. J. (1996). Life course sequelae of childhood shyness in Sweden: Comparison with the United States. Developmental Psychology, 32, 1100-1105.

Kim, J., Rapee, R., Oh, K., \& Moon, H. (2008). Retrospective report of social withdrawal during adolescence and current maladjustment in young adulthood: Cross-cultural comparisons between Australian and South Korean students. Journal of Adolescence, 31, 543-563.

Larson, R. W. (1990). The solitary side of life: An examination of the time people spend alone from childhood to old age. Developmental Review, 10, 155-183.

Larson, R. W. (1997). The emergence of solitude as a constructive domain of experience in early adolescence. Child Development, 68, 80-93.

Larson, R. W., \& Csikszentmihalyi, M. (1978). Experiential correlates of time alone in adolescence. Journal of Personality, 46, 677-693.

Leck, K. (2006). Correlates of minimal dating. The Journal of Social Psychology, 146(5), 549-567.

Lieberman, M., Gauvin, L., Bukowski, W. M., \& White, D. R. (2001). Interpersonal influence and disordered eating behaviors in adolescent girls: The role of peer modeling, social reinforcement, and body-related teasing. Eating Behaviors: An International Journal, 2, 215-236.

Luster, S. S., Nelson, L. J., \& Busby, D. M. (in press). Shyness and communication: Impacts on self- and partner relationship satisfaction. Journal of Couple and Relationship Therapy.

Luster, S. S., Nelson, L. J., Poulsen, F. O., \& Willoughby, B. J. (in press). Emerging adult sexual attitudes and behaviors: Does shyness matter? Emerging Adulthood.

Markovic, A., Rose-Krasnor, L., \& Coplan, R. J. (2013). Shy children's coping with a social conflict: The role of personality self-theories. Personality and Individual Differences, 54(1), 64-69.

Melchior, L. A., \& Cheek, J. M. (1990). Shyness and anxious self preoccupation during a social interaction. Journal of Social Behavior and Personality, 5, 117-130.

Mounts, N., Valentiner, D., Anderson, K., \& Boswell, M. (2006). Shyness, sociability, and parental support for the college transition: Relation to adolescents' adjustment. Journal of Youth and Adolescence, 35(1), 68-77. 
Muris, P., Merckelbach, H., Schmidt, H., Gadet, B., \& Bogie, N. (2001). Anxiety and depression as correlates of self-reported behavioural inhibition in normal adolescents. Behavior Research and Therapy, 39(9), 1051-1061.

Nelson, L. J. (2013). Going it alone: Comparing subtypes of withdrawal on indices of adjustment and maladjustment in emerging adulthood. Social Development, 22, 522-538.

Nelson, L. J., Padilla-Walker, L. M., Badger, S., Barry, C. M., Carroll, J. S., \& Madsen, S. D. (2008). Associations between shyness and internalizing behaviors, externalizing behaviors, and relationships during emerging adulthood. Journal of Youth and Adolescence, 37(5), 605-615.

Nelson, L. J., Padilla-Walker, L. M., Carroll, J. S., Madsen, S. D., Barry, C. M., \& Badger, S. (2007). 'If you want me to treat you like an adult, start acting like one!' Comparing the criteria that emerging adults and their parents have for adulthood. Journal of Family Psychology, 21(4), 665-674.

Neto, F. (2001). Personality predictors of happiness. Psychological Reports, 88(3), 817-824.

Oh, W., Rubin, K. H., Bowker, J. C., Booth-LaForce, C., Rose-Krasnor, L., \& Laursen, B. (2008). Trajectories of social withdrawal from middle childhood to early adolescence. Journal of Abnormal Child Psychology, 36(4), 553-566.

Phillips, S. D., \& Bruch, M. A. (1988). Shyness and dysfunction in career development. Journal of Counseling Psychology, 35, 159-165.

Piaget, J. (1932). The moral judgment of the child. New York: Harcourt, Brace Jovanovich.

Prior, M., Smart, D., Sanson, A., \& Oberklaid, F. (2000). Does shy-inhibited temperament in childhood lead to anxiety problems in adolescence? Journal of the American Academy of Child and Adolescent Psychiatry, 39(4), 461-468.

Ricciardelli, L. A., \& McCabe, M. P. (2001). Children's body image concerns and eating disturbance: A review of the literature. Clinical Psychology Review, 21, 325-344.

Rowsell, H. C., \& Coplan, R. J. (2012). Exploring links between shyness, romantic relationship quality, and well-being. Canadian Journal of Behavioural Science. doi:10.1037/a0029853.

Rubin, K. H., Bukowski, W., \& Parker, J. (2006). Peer interactions, relationships, and groups. In N. Eisenberg (Ed.), Handbook of child psychology (6th edition): Social, emotional, and personality development (pp. 571-645). New York: Wiley.

Rubin, K. H., Coplan, R. J., \& Bowker, J. C. (2009). Social withdrawal and shyness in childhood. Annual Review of Psychology, 60, 141-171.

Rubin, K. H., Wojslawowicz, J. C., Rose-Krasnor, L., Booth-LaForce, C., \& Burgess, K. B. (2006b). The best friendships of shy/withdrawn children: Prevalence, stability, and relationship quality. Journal of Abnormal Child Psychology, 34(2), 143-157.

Sullivan, H. S. (1953). The interpersonal theory of psychiatry. New York: Norton.

Woodhouse, S. S., Dykas, M. J., \& Cassidy, J. (2012). Loneliness and peer relations in adolescence. Social Development, 21(2), 273-293. 